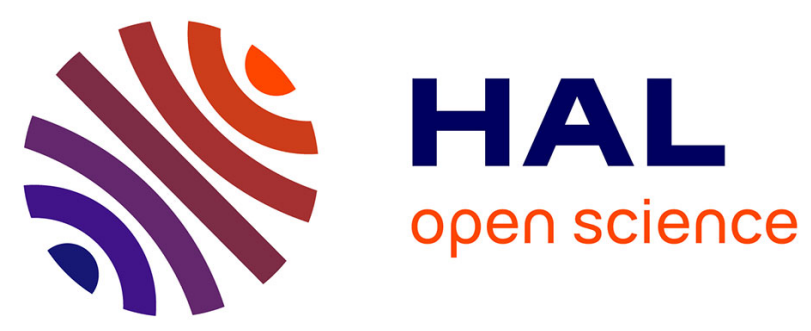

\title{
Adsorption mechanism of aligned single wall carbon nanotubes at well defined metal surfaces
}

Sylvain Clair, Caroline Rabot, Yousoo Kim, Maki Kawai

\section{To cite this version:}

Sylvain Clair, Caroline Rabot, Yousoo Kim, Maki Kawai. Adsorption mechanism of aligned single wall carbon nanotubes at well defined metal surfaces. Journal of Vacuum Science \& Technology B Microelectronics and Nanometer Structures, 2007, 25 (4), 10.1116/1.2743652 . hal-01896174

\section{HAL Id: hal-01896174 \\ https://hal-amu.archives-ouvertes.fr/hal-01896174}

Submitted on 6 Apr 2020

HAL is a multi-disciplinary open access archive for the deposit and dissemination of scientific research documents, whether they are published or not. The documents may come from teaching and research institutions in France or abroad, or from public or private research centers.
L'archive ouverte pluridisciplinaire HAL, est destinée au dépôt et à la diffusion de documents scientifiques de niveau recherche, publiés ou non, émanant des établissements d'enseignement et de recherche français ou étrangers, des laboratoires publics ou privés. 


\title{
Adsorption mechanism of aligned single wall carbon nanotubes at well defined metal surfaces
}

\author{
Sylvain Clair and Caroline Rabot \\ RIKEN (The Institute of Physical and Chemical Research), 2-1 Hirosawa, Wako, Saitama 351-0198, Japan \\ and Department of Advanced Materials Science, The University of Tokyo, Chiba 277-8561, Japan \\ Yousoo $\mathrm{Kim}^{\mathrm{a}), \mathrm{b})}$ \\ RIKEN (The Institute of Physical and Chemical Research), 2-1 Hirosawa, Wako, Saitama 351-0198, Japan \\ Maki Kawai ${ }^{a), c)}$ \\ RIKEN (The Institute of Physical and Chemical Research), 2-1 Hirosawa, Wako, Saitama 351-0198, Japan \\ and Department of Advanced Materials Science, The University of Tokyo, Chiba 277-8561, Japan
}

(Received 10 January 2007; accepted 30 April 2007; published 12 June 2007)

\begin{abstract}
In situ dry deposition of individual single wall carbon nanotubes on metal surfaces has been studied by scanning tunneling microscopy. The nanotubes are lying parallel over large areas, with a preferential adsorption along the substrate lattice directions, for which the nanotube-surface interaction is maximized. The authors propose a mechanism for the deposition process, where the aligned geometry results from a selective transfer of the nanotubes depending on their orientation relative to the substrate. (ㅇ 2007 American Vacuum Society. [DOI: 10.1116/1.2743652]
\end{abstract}

\section{INTRODUCTION}

In order to produce large-scale applications utilizing the exceptional properties of carbon nanotubes (CNTs) many challenges must be overcome. Important problems to integrate CNT into functional devices concern the selective positioning on a substrate and the connection to the metal electrodes. A good control on both points is a key issue for developing industry-relevant devices. ${ }^{1}$

In the view of nanotube positioning, several approaches have proven to be successful. In-plane control of nanotube alignment can be achieved either during the growth process by electrical field, ${ }^{2}$ gas flow, ${ }^{3}$ lattice directions and graphoepitaxy, ${ }^{4-8}$ or in situ on a graphite substrate ${ }^{9}$ or by selective deposition of functionalized tubes. ${ }^{10}$ In recent years, Lyding and co-workers demonstrated the alignment of pristine carbon nanotubes with the substrate crystallographic directions on various semiconducting surfaces. ${ }^{11-13}$ Their approach consists of a vacuum dry deposition that results in the transfer of primarily isolated, individual nanotubes on an unperturbed surface. All the reported results on nanotube alignment were obtained on nonmetal surfaces. In this article we extend the approach of Lyding and co-workers ${ }^{11-13}$ to the well defined surfaces $\mathrm{Au}(111), \mathrm{Cu}(111)$, and $\mathrm{Cu}(001)$. Similarly, nanotube alignment was obtained, providing therefore the first achievement of an in-plane control of the orientation of carbon nanotubes on several metal surfaces.

A large number of investigations on single wall carbon nanotubes (SWCNTs) by means of scanning tunneling microscopy (STM) have been reported, but they are mostly restricted to $\mathrm{Au}(111)$ surfaces, ${ }^{14-19}$ as the CNTs were brought to the substrate through the deposition of a droplet of solvent

\footnotetext{
a) Authors to whom correspondence should be addressed.

${ }^{b)}$ Electronic mail: ykim@ @iken.jp

c) Electronic mail: maki@riken.jp
}

dispersion in ambient or argon atmosphere conditions. In this case, a large number of coadsorbed impurities are found surrounding the nanotubes and therefore limit the investigations to the nanotube itself, regardless of its environment. Recently, pulse valve deposition was successfully demonstrated for multiwall nanotubes on a semiconducting surface ${ }^{20}$ and for double wall $\mathrm{CNT}$ on $\mathrm{Cu}(111),{ }^{21}$ leading to a relative increase of the cleanliness of the system. Conversely, the contaminant-free dry deposition opens new ways for studying the effects arising from the interaction of carbon nanotubes and the underlying surface. In molecular electronics, the conduction properties of devices are restricted to the interface conditions with the metal electrodes. ${ }^{1}$ The delicate issue of the metal-nanotube contact is still a subject of discussion, ${ }^{22-24}$ and STM investigations can deliver precious insight.

Based on our STM observations, we propose a mechanism for the vacuum deposition process, thus revealing the driving force originating the alignment. This result suggests that in a proper experimental setup, highest control of the nanotube positioning may be achieved with this technique.

\section{EXPERIMENTAL METHOD}

The measurements were performed in an ultrahigh vacuum (UHV) low-temperature STM with a base temperature of $4.7 \mathrm{~K}$ (Omicron LT-STM). The $\mathrm{Au}(111), \mathrm{Cu}(111)$, and $\mathrm{Cu}(001)$ single crystals were cleaned following standard UHV procedures by repeated cycles of argon ion sputtering and annealing providing atomically clean surfaces. SWCNTs were deposited onto the surface following the dry contact transfer (DCT) technique proposed by Albrecht and Lyding: ${ }^{11}$ a copper braid was macroscopically covered by a HiPco nanotube ${ }^{25}$ dispersion in dichloroethane, then introduced in UHV and brought into direct contact with the clean sample surface at room temperature. 


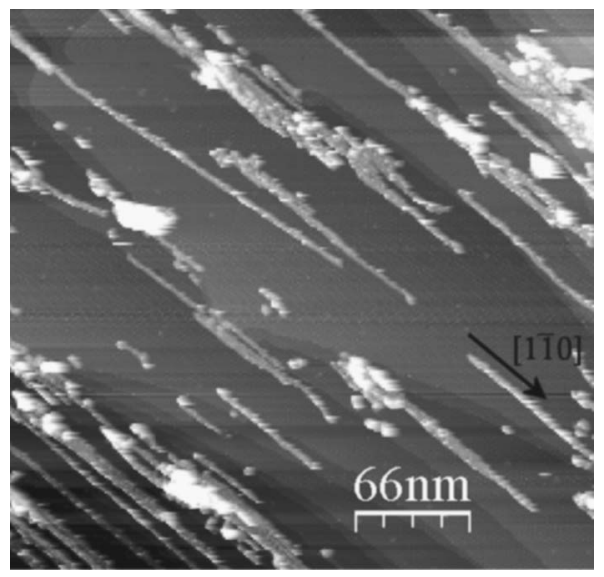

FIG. 1. Typical STM observation after DCT deposition [here on $\mathrm{Cu}(001)$ ]. The carbon nanotubes are lying parallel along the [110] direction over large areas (tunneling current of $0.3 \mathrm{nA}$, sample bias of $+1 \mathrm{~V}$ ).

\section{RESULTS AND DISCUSSION}

The vacuum deposition by dry contact transfer results primarily in isolated individual nanotubes. The nanotube density is very inhomogeneous over the surface, with large macroscopic areas completely free of nanotubes. Figure 1 shows the typical configuration obtained on $\mathrm{Cu}(001)$, and is representative also for the $\mathrm{Cu}(111)$ and $\mathrm{Au}(111)$ cases. All nanotubes are lying parallel, in a direction close to the surface high symmetry $[1 \overline{1} 0]$ direction. Atomically resolved images on both the substrate and the nanotube show occasionally an exact correspondence of the substrate atomic row and the nanotube axis, similar to what was observed on semiconducting surfaces. ${ }^{11-13}$ When identifying the different nanotube types following the procedure described by Wildöer et al. ${ }^{15}$ (where the geometry can be extracted from the measurement of the diameter, the chiral angle, and the gap width), the expected distribution of $1 / 3$ metallic and $2 / 3$ semiconducting was roughly found, ${ }^{26}$ as well as the standard diameter distribution (around $1 \mathrm{~nm}$ ).

In general, on the entire area reached by the piezoelectric scanner $\left(\sim 1 \times 1 \mu \mathrm{m}^{2}\right)$ all nanotubes are lying parallel. However, when changing macroscopically the position of the tip, different alignment directions can be observed. We performed statistical measurements of the orientation angle in the STM images for the nanotubes observed on about 30 macroscopically different regions and for the crystal surfaces $\mathrm{Au}(111), \mathrm{Cu}(111)$, and $\mathrm{Cu}(001)$. The resulting histograms are shown in Fig. 2. On (111)-oriented surfaces, about 3/4 of the nanotubes were found aligned within $\pm 10^{\circ}$ with the substrate

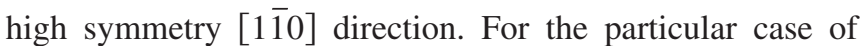
$\mathrm{Cu}(001), 30 \%$ of the nanotubes were aligned within $\pm 10^{\circ}$ with the $[1 \overline{1} 0]$ direction while $70 \%$ were aligned with the bisecting [010] direction. This anisotropic distribution has to be related to the fact that the adsorption of a nanotube on a well defined surface exhibits strongly localized energy potential wells depending on the orientation angle. ${ }^{27}$ The alignment remains globally unchanged after annealing the sample up to $500 \mathrm{~K}$, showing that the configuration obtained is ther-

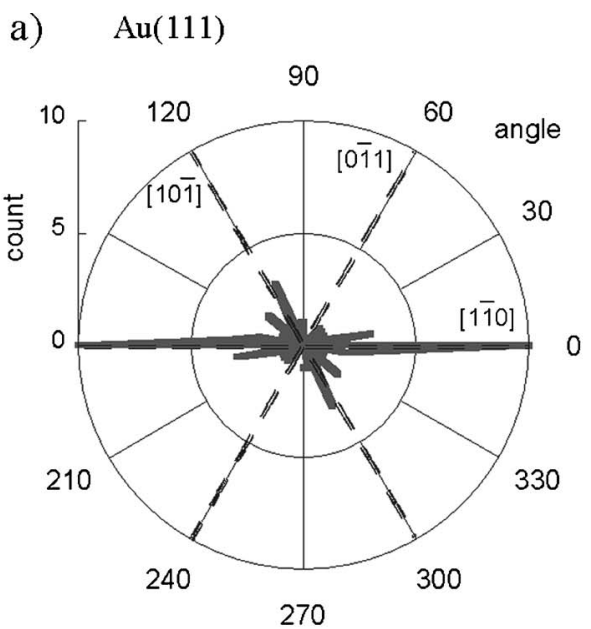

b) $\mathrm{Cu}(001)$

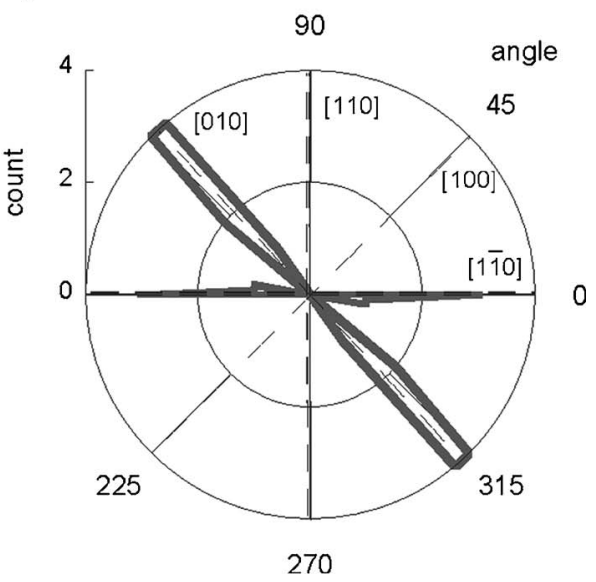

FIG. 2. Angular distributions derived from STM observations: the angle between nanotube orientation and the [1ㅣㅣ direction of the crystal was measured in different macroscopic regions; the histogram shows the corresponding statistics. On $\mathrm{Au}(111)$ (a) and on $\mathrm{Cu}(111)$ (not shown), the CNTs are mostly aligned along the $[1 \overline{1} 0]$ high symmetry directions. $\mathrm{On} \mathrm{Cu}(001)$ (b), nanotubes are found along the [1 $\overline{1} 0]$ high symmetry direction as well as along the bisecting direction [010]. Note, however, that the crystal surface was not systematically investigated on a macroscopic scale.

modynamically stable. The symmetry break observed is therefore related to the specific deposition process used (as a comparison, CNTs deposited on a $\mathrm{Au}(111)$ surface from a solution droplet do not show any preferential orientation ${ }^{18}$ ).

In our experimental setup, the movement by which the thick CNT film on the copper braid comes into contact with the crystal surface during the DCT process is governed by hand and therefore not precisely controlled on the micrometer scale. The relative motion is globally normal to the surface but possesses also a tangential component that defines the horizontal alignment direction after deposition. We performed scanning electron microscope (SEM) measurements on the copper braid used for the DCT deposition (Fig. 3). Typically, islands about $10 \mu \mathrm{m}$ wide are found, which upper surface has been flattened due to the contact with the crystal surface. On top of each island a global nanotube alignment is observed. The alignment direction differs, however, from one 


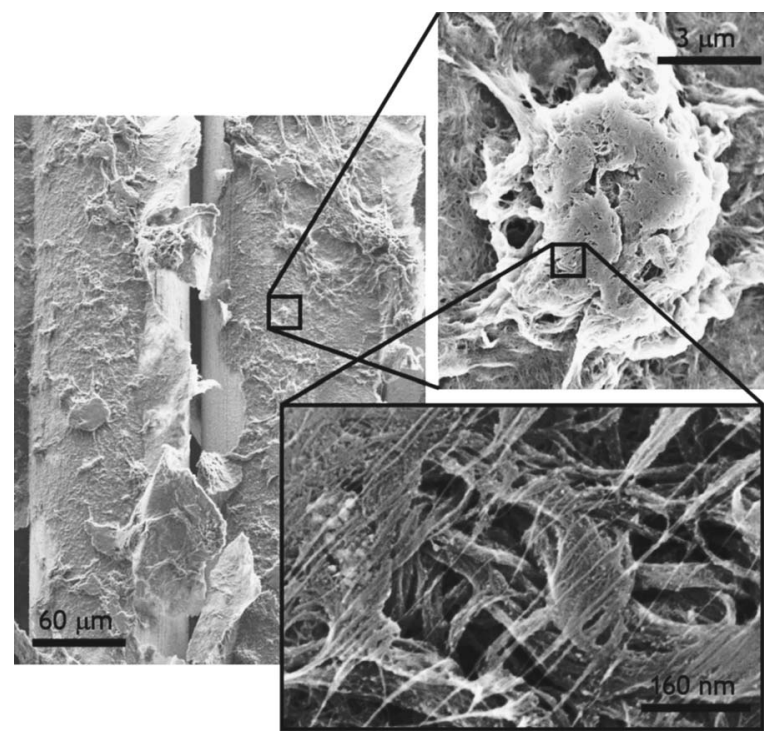

FIG. 3. SEM micrographs of the copper braid used for DCT deposition. Small islands that have been flattened during the contact with the deposited surface are found (top right). On their upper surface, nanotubes are stretched along a defined direction (bottom right).

island to the other. This results from different contacting trials on the same braid, that are necessary in order to produce a reasonable nanotube density on the crystal surface. On the rest of the braid, the CNT film consists of a rather flat, dense, and disordered bundle network, where the intertube cohesion is high. Individual nanotubes or small bundles appear only in locally damaged regions protruding out of the film.

In view of these findings, we propose the following mechanism for the DCT deposition. When the crystal surface approaches the CNT film on the applicator, the prominent parts of the film come into contact and form the islands of Fig. 3. These parts consist mostly of separated weakly bonded nanotubes or small bundles which are easily transferred. The local lateral friction defines a unique privileged direction. We exclude the possibility for the nanotubes to be first transferred to the crystal surface regardless of their orientation, and then relax within a few tens of degrees in order to find the closest direction of lowest energy. At room temperature the mobility of CNT is rather limited ${ }^{16}$ and this thermally activated process would lead to a misalignment distribution, in particular, in function of nanotube length. This statement is denied by the STM observations (Fig. 1). Rather we believe that, in order for the nanotubes to be effectively transferred to the metallic surface, substantial attractive interaction is required, which acts as a filtering step. The transfer can only take place if this interaction is sufficiently high, i.e., when the nanotube is aligned with a substrate atomic row where the adsorption energy is maximized. ${ }^{27}$ The transfer process is therefore highly selective and governed by the strong directional nanotube-surface interaction, regardless of the nanotube type (metallic or semiconducting) and geometry (diameter and chiral indices).
The deposition process can thus be regarded as a combination of the microcontact printing lithography technique, ${ }^{28}$ where the deposition takes place at the micrometer scale, and the rubbing method, where buffing a polymer film with a cloth produces long range molecular alignment. ${ }^{29-31}$

In summary, we have reported the first application of dry contact transfer (DCT) of single wall carbon nanotubes on metal surfaces. We found a selective adsorption of the nanotubes along the $\langle 1 \overline{1} 0\rangle$ directions of $\mathrm{Au}(111)$ and $\mathrm{Cu}(111)$ and along the $\langle 1 \overline{1} 0\rangle$ and $\langle 100\rangle$ directions of $\mathrm{Cu}(001)$. The deposition process leads to a systematic alignment of the nanotubes. We believe that with a proper experimental setup allowing a precise control on the contacting motion during deposition, selective placement of carbon nanotubes along a unique direction and with micrometer precision could be achieved with the DCT method.

\section{ACKNOWLEDGMENTS}

H. Kohinata is gratefully acknowledged for the acquisition of the SEM pictures. The authors wish to thank B. Grandidier for fruitful discussions.

${ }^{1}$ M. S. Dresselhaus, G. Dresselhaus, and P. Avouris, Carbon Nanotubes: Synthesis, Structure, Properties and Applications (Springer, Berlin, 2001), Vol. 80.

${ }^{2}$ A. Ural, Y. Li, and H. Dai, Appl. Phys. Lett. 81, 3464 (2002).

${ }^{3}$ S. Huang, M. Woodson, R. Smalley, and J. Liu, Nano Lett. 4, 1025 (2004).

${ }^{4}$ A. Ismach, L. Segev, E. Wachtel, and E. Joselevich, Angew. Chem., Int. Ed. 43, 6140 (2004)

${ }^{5}$ S. Han, X. Liu, and C. Zhou, J. Am. Chem. Soc. 127, 5294 (2005).

${ }^{6}$ C. Rettig, M. Bodecker, and H. Hovel, J. Phys. D 36, 818 (2003).

${ }^{7}$ J. H. Yi and M. A. E. Khakani, Chem. Phys. Lett. 413, 182 (2005).

${ }^{8}$ H. Ago, K. Nakamura, K.-I. Ikeda, N. Uehara, N. Ishigami, and M. Tsuji, Chem. Phys. Lett. 408, 433 (2005).

${ }^{9}$ H. Yanagi, E. Sawada, A. Manivannan, and L. A. Nagahara, Appl. Phys. Lett. 78, 1355 (2001).

${ }^{10}$ C. Klinke, J. B. Hannon, A. Afzali, and P. Avouris, Nano Lett. 6, 906 (2006).

${ }^{11}$ P. M. Albrecht and J. W. Lyding, Appl. Phys. Lett. 83, 5029 (2003).

${ }^{12}$ L. B. Ruppalt, P. M. Albrecht, and J. W. Lyding, J. Vac. Sci. Technol. B 22, 2005 (2004).

${ }^{13}$ L. B. Ruppalt, P. M. Albrecht, and J. W. Lyding, J. Phys. IV 132, 31 (2006).

${ }^{14}$ T. W. Odom, J.-L. Huang, P. Kim, and C. M. Lieber, Nature (London) 391, 62 (1998).

${ }^{15}$ J. W. G. Wildoer, L. C. Venema, A. G. Rinzler, R. E. Smalley, and C. Dekker, Nature (London) 391, 59 (1998).

${ }^{16}$ A. Hassanien, M. Tokumoto, T. Shimizu, and H. Tokumoto, Thin Solid Films 464-465, 338 (2004).

${ }^{17}$ J. Lee, S. Eggert, H. Kim, S.-J. Kahng, H. Shinohara, and Y. Kuk, Phys. Rev. Lett. 93, 166403 (2004).

${ }^{18}$ T. W. Odom, J.-L. Huang, P. Kim, M. Ouyang, and C. M. Lieber, J. Mater. Res. 13, 2380 (1998)

${ }^{19}$ L. Vitali, M. Burghard, M. A. Schneider, L. Liu, S. Y. Wu, C. S. Jayanthi, and K. Kern, Phys. Rev. Lett. 93, 136103 (2004).

${ }^{20}$ Y. Terada, B.-K. Choi, S. Heike, M. Fujimori, and T. Hashizume, Jpn. J. Appl. Phys., Part 1 42, 4739 (2003).

${ }^{21}$ N. Fukui et al. (unpublished).

${ }^{22}$ X. Cui, M. Freitag, R. Martel, L. Brus, and P. Avouris, Nano Lett. 3, 783 (2003).

${ }^{23}$ Z. Chen, J. Appenzeller, J. Knoch, Y.-M. Lin, and P. Avouris, Nano Lett. 5, 1497 (2005) 
${ }^{24}$ N. Nemec, D. Tomanek, and G. Cuniberti, Phys. Rev. Lett. 96, 076802 (2006).

${ }^{25}$ Carbon Nanotechnologies Inc.

${ }^{26}$ C. T. White and J. W. Mintmire, J. Phys. Chem. B 109, 52 (2005).

${ }^{27}$ A. N. Kolmogorov, V. H. Crespi, M. H. Schleier-Smith, and J. C. Ellenbogen, Phys. Rev. Lett. 92, 085503 (2004).
${ }^{28}$ Y. Xia and G. M. Whitesides, Angew. Chem., Int. Ed. 37, 550 (1998).

${ }^{29}$ M. B. Feller, W. Chen, and Y. R. Shen, Phys. Rev. A 43, 6778 (1991).

${ }^{30}$ M. F. Toney, T. P. Russell, J. A. Logan, H. Kikuchi, J. M. Sands, and S.

K. Kumar, Nature (London) 374, 709 (1995).

${ }^{31}$ K. Sakamoto, R. Arafune, N. Ito, S. Ushioda, Y. Suzuki, and S. Morokawa, J. Appl. Phys. 80, 431 (1996). 